Report

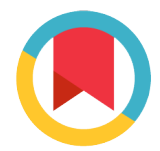

Check for updates
*For correspondence:

salman.khazaei61@gmail.com

Competing interests: The authors declare that no competing interests exist.

Received: 03 July 2017

Accepted: 21 July 2017

Published: 28 July 2017

Copyright The Author(s) 2017. This article is published with open access by BioMedPress (BMP).

This article is distributed under the terms of the Creative Commons Attribution License (CC-BY 4.0) which permits any use, distribution, and reproduction in any medium, provided the original author(s) and the source are credited.

\section{Inequality in Human Development Index and suicide death in Iran: A National Register-Based Study}

\section{Yousef Veisani ${ }^{1}$, Ali Delpisheh ${ }^{2}$, Fathola Mohamadian³ ${ }^{3}$ Maryam Baghri $^{4}$, Salman Khazaei ${ }^{5, *}$}

\author{
${ }^{1}$ Psychosocial Injuries Research Center, Ilam University of Medical Sciences, Ilam, Iran \\ ${ }^{2}$ Department of Clinical Epidemiology, Ilam University of Medical Sciences, Ilam-Iran \\ ${ }^{3}$ Department of Psychology, Psychosocial Injuries Research Center, Ilam University of \\ Medical Sciences, Ilam, Iran \\ ${ }^{4}$ Department of Physiology, Psychosocial Injuries Research Center, Ilam University of \\ Medical Sciences, Ilam, Iran \\ ${ }^{5}$ Department of Epidemiology, School of Public Health, Hamadan University of Medical \\ Sciences, Hamadan, Iran
}

\section{Abstract}

Pay attention to the effects of inequality in health outcomes has steadily risen during recent years. It is necessary step to achieve the goal of health for all (HFA) in the coming decades. At the moment, our knowledge about the inequality and suicide is limited. Human Development Index (HDI) is summary measures that we can demonstrate current inequalities regarded to health outcomes. We have reanalyzed the national data by Statistical Centre of Iran for HDI and Iranian Forensic Medicine Organization for suicide to explicate of inequality in suicide death in Iran. Our results showed an inverse correlation between $\mathrm{HDI}$ and suicide death, so that deaths from suicide was more occurred in provinces with lower HDI. Therefore, results in current study showed a positive inequality in suicide in relation with $\mathrm{HDI}$ in Iran. According to this, we suggested that regional studies will be conducted to detect subgroups with a high suicide risk as well as components of HDI that cause inequality.

\section{Keywords}

Human Development Index (HDI), Inequality, Socioeconomic, Suicide 


\section{Introduction}

Suicide is considered as an important public health problem in both developing and developed countries, which lead to more than 800,000 deaths annually (Noorbala AA, 1998). The effects of inequality in health have been acknowledged in developed countries (Veisani et al., 2017). Researchers now aimed to reducing the inequalities in the coming decades through enhance knowledge about inequality sources. The connection between socioeconomic status (SES) and suicide has been controversial. Some have found that a deprived situations increasing the risk of suicide (Burrows and Laflamme, 2010; Yoder and Hoyt, 2005), while other concluded oppose it (Chan et al., 2009), this diversity may be due to variety in methods being used to measure SES. Human Development Index (HDI) is summary measures that can be demonstrated current inequalities and poverty in different contraries. In current study we aimed to obtain the relationship between inequality in HDI and suicide death in Iran using national data.

\section{Materials-Methods}

This is an ecological study on the relation of HDI and suicide death in Iran. Data obtained from Results of the Iranian Urban and Rural Household Income and Expenditure Survey in 2013 for HDI (Noorbala and Akhondzadeh, 2015), and the annual reports of Iranian Forensic Medicine Organization in 2012 for suicide rate (Kiadaliri et al., 2014). In this study, we defined inequality in the suicide death according to the $\mathrm{HDI}$ by using concentration index $(\mathrm{Cl})$ among provinces. The value of $\mathrm{Cl}$ is between -1 to +1 and the negative value of this index is indicating that the related variable to health is more concentrated on the poor population and the positive value indicates that the related variable to health concentrated among the rich population (Mohammadi et al., 2003). We used the Stata software version 12 (Stata Corp, College Station, TX, USA) to perform all the analytical operations as well as Epi Info ${ }^{\mathrm{TM}}$ software for drawing maps. Significant level considered less than $5 \%$.

\section{Results}

As shown in Figure 1, suicide rate in Iran ranged from 2.21 to 19.53 per 100,000 populations (average rate: 5.1). Among all provinces highest rate observed in Ilam with 19.53 and lowest in Hormozgan with 2.21 per 100,000 population. In addition, slightly more than half (56.6\%) provinces had a suicide rate of 3-6 per 100,000 populations. Also figure 1 shown the HDI level for all provinces, accordingly Sistan \& Baluchestan and Tehran had a lowest and highest rank 
(0.643 and 0.843), respectively. The $\mathrm{Cl}$ is presented in Figure $\overline{2}$, which shows that suicide was more occurred in provinces with lower $\mathrm{HDI}$. The overall $\mathrm{Cl}$ was $-0.234(95 \% \mathrm{Cl}=-0.343$ to -0.124$)$. Therefore our results confirmed a positive inequality in suicide death result from HDI in Iran. A predictor graph was shown in Figure 3. It is evident that the higher HDI was associated with lower suicide death in Iran $(r=-0.089, p<0.001)$.
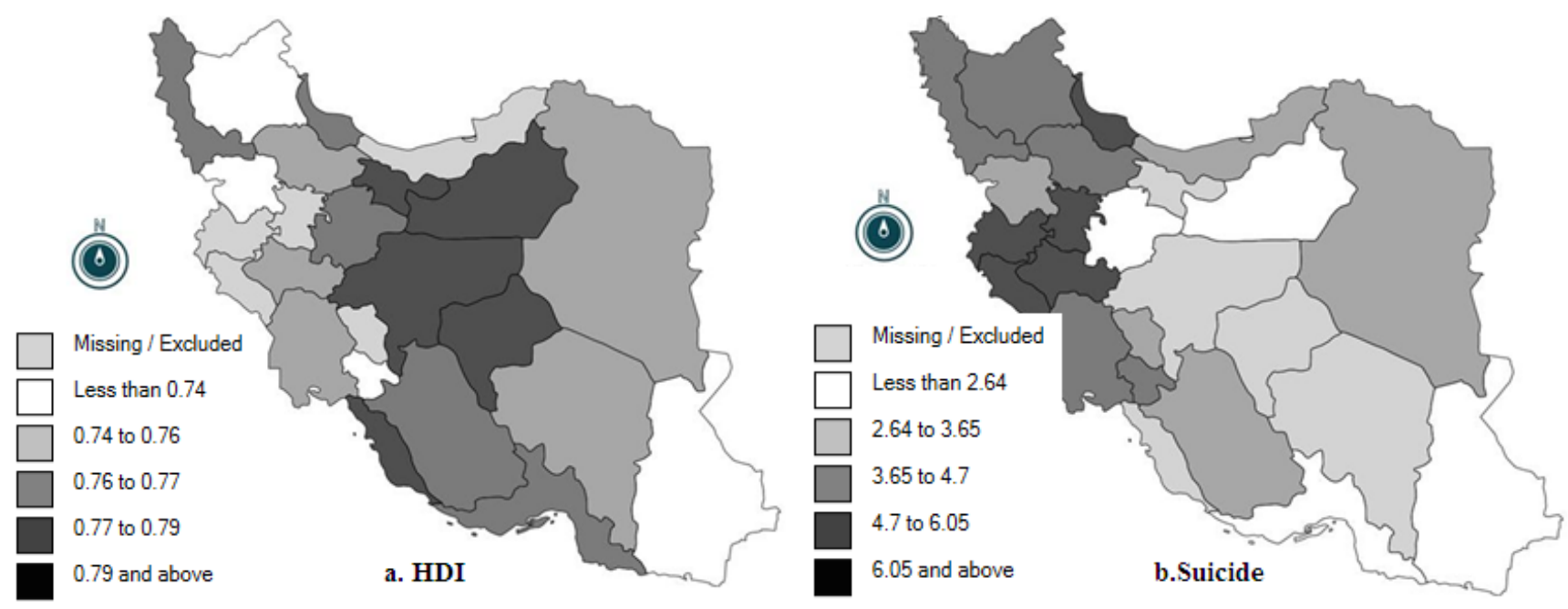

Figure 1. HDI level (A) and suicide rate (B) by province in 2013.

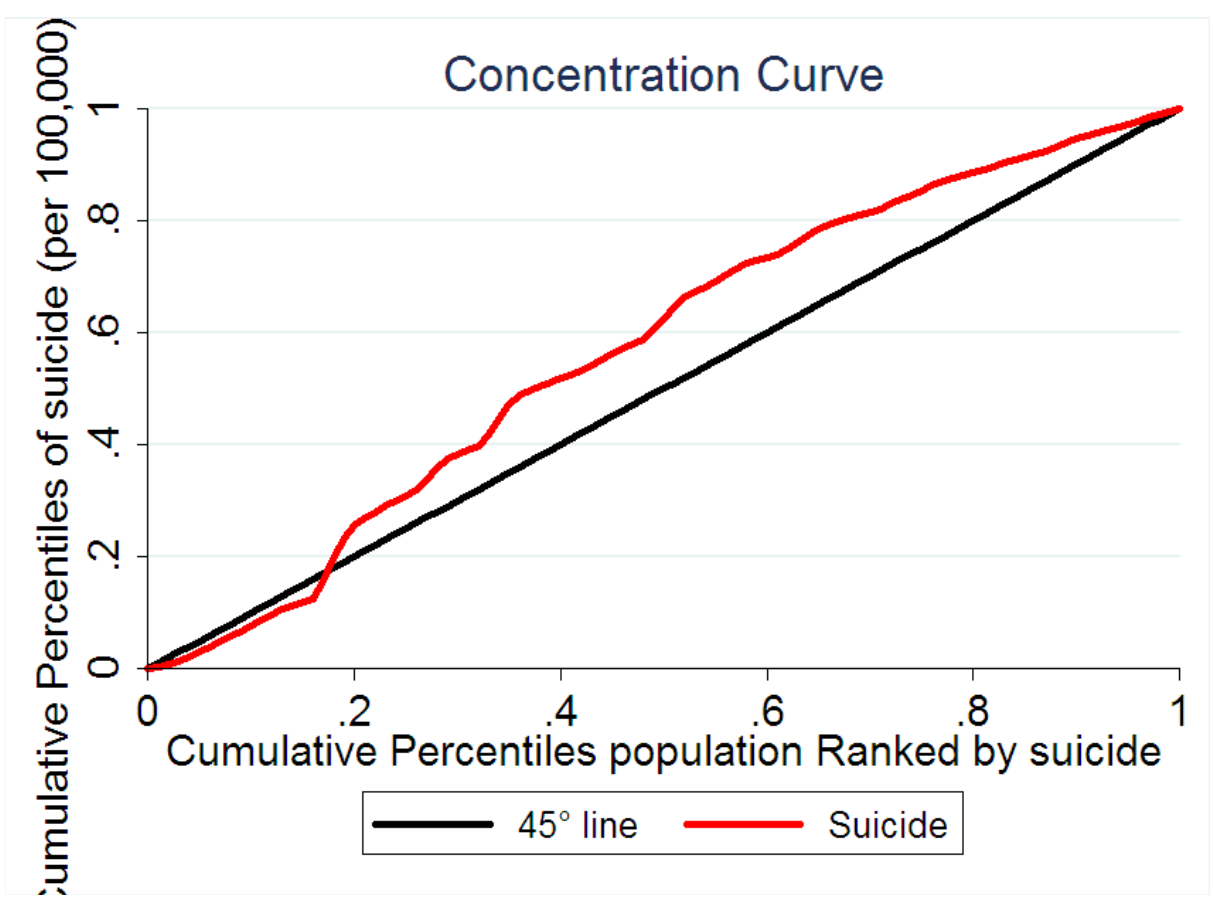

Figure 2. Concentration curve for relation between suicide rate and HDI level. 


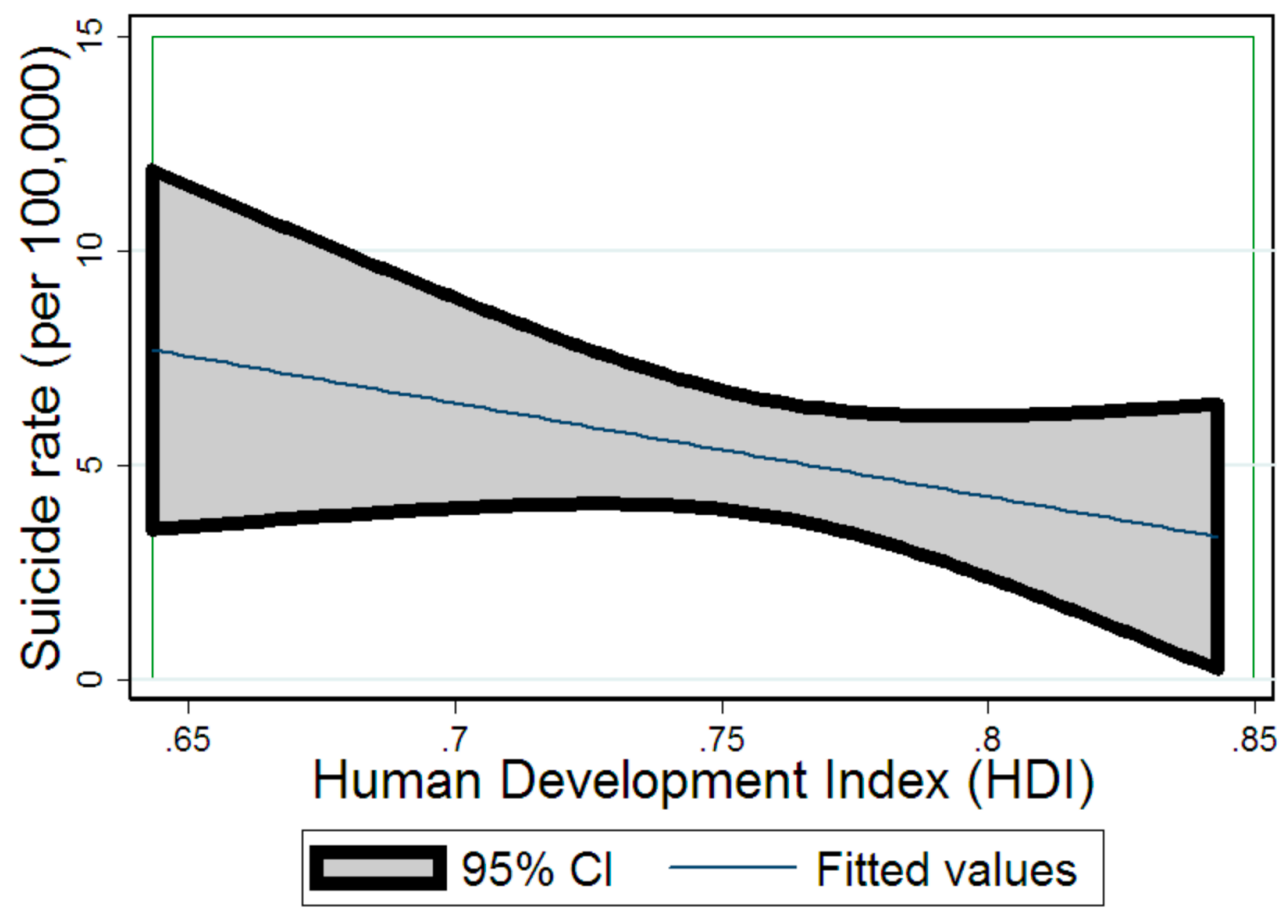

Figure 3. Predictor graph for suicide rate according HDI range.

\section{Discussion}

Our results were showed an inverse correlation between the HDI and suicide death in Iran. It comes to mind that people in the provinces with lower HDI rank generally have lower key dimensions of human development such as have a decent standard of living, a long and healthy life and being knowledgeable. The interesting point in our study is that provinces with high rank of suicide death such as Ilam (Veisani et al., 2016), Kermanshah, Lorestan and Hamadan (rank first to fourth) have a lowest HDI according to figure 1. One potential explanation for this finding can be the low SES of these provinces (Veisani and Delpisheh, 2015). This finding is in line with previous systematic review that found, $73 \%$ of previous studies had an inverse association between education level and suicide death and as well in relation to income and suicide in $50 \%$ of them. They also indicated that $94 \%$ of studies that preformed in Asia reign had a significant negative relationship between social rank and suicide death (Pearce et al., 2007). 


\section{Conclusion}

In summary, the present study indicated that a positive inequality in suicide death rate relation to $\mathrm{HDI}$ in Iran. According to this important finding more studies are needed to explore the origin of inequality in local area to design and apply of intervention programs in provinces especially with high prevalence rate of suicide.

\section{Abbreviations}

Human Development Index (HDI)

Socioeconomic status (SES)

Concentration index $(\mathrm{Cl})$

\section{Author contribution}

All authors contributed in manuscript preparation. Veisani,Y and Khazaei,S obtained data and analyzed it. Delpisheh,A and Baghri,M interpreted of data analysis. Mohamadian, $F$ designed of figures. All authors drafted the first version and approve the final draft. 


\section{Biomedical Research \& Therapy}

ISSN: 2198-4093

www.bmrat.org

\section{References}

Burrows, S., and Laflamme, L. (2010). Socioeconomic disparities and attempted suicide: state of knowledge and implications for research and prevention. International journal of injury control and safety promotion 17, 23-40.

Chan, W.S., Law, C.K., Liu, K.Y., Wong, P.W., Law, Y.W., and Yip, P.S. (2009). Suicidality in Chinese adolescents in Hong Kong: the role of family and cultural influences. Social psychiatry and psychiatric epidemiology 44, 278-284.

Kiadaliri, A.A., Saadat, S., Shahnavazi, H., and Haghparast-Bidgoli, H. (2014). Overall, gender and social inequalities in suicide mortality in Iran, 2006-2010: a time trend province-level study. BMJ open 4, e005227.

Mohammadi, M., Rahgozar, M., Bagheri Yazdi, A., Naghavi, H., Pour Etemad, H.R., Amini, H., Rostami, M., and Mesgarpour, B. (2003). Epidemiological Study of Psychiatric Disorders in Tehran Province. Iranian Journal of Psychiatry and Clinical Psychology 9, 4-13.

Noorbala, A.A., and Akhondzadeh, S. (2015). Mental health study process into prevalence of mental disorders in iran. Arch Iran Med 18, 74-75.

Noorbala AA, M.K., Bagheri Yazdi SA (1998). The epidemiological study of psychiatric disorders in Tehran. J Hakim 4, 212-223.

Pearce, J., Barnett, R., Collings, S., and Jones, I. (2007). Did geographical inequalities in suicide among men aged 15-44 in New Zealand increase during the period 1980 2001? Australian \& New Zealand Journal of Psychiatry 41, 359-365.

Veisani, Y., and Delpisheh, A. (2015). Decomposing of socioeconomic inequality in mental health: a cross-sectional study into female-headed households. Journal of research in health sciences 15, 218-222.

Veisani, Y., Delpisheh, A., Sayehmiri, K., Moradi, G., and Hassanzadeh, J. (2016). Suicide attempts in Ilam Province, Western Iran, 2010-2014: a time trend study. Journal of research in health sciences 16, 64-67.

Veisani, Y., Moradi, G., and Delpisheh, A. (2017). Effects of Socio-economic Status Inequality on Health Outcomes. Arch Iran Med 20, 329.

Yoder, K.A., and Hoyt, D.R. (2005). Family economic pressure and adolescent suicidal ideation: application of the family stress model. Suicide and Life-Threatening Behavior $35,251-264$. 